\title{
Removal of AC interference from the electrocardiogram
}

\author{
H. MOSELEY AND J. A. KENNEDY \\ From West of Scotland Health Boards, Department of Clinical Physics and Bio-Engineering, Glasgow \\ and the Cardiac Department, Western Infirmary, Glasgow
}

\begin{abstract}
$A$ method is described for the removal of $A C$ interference from the electrocardiogram in monitors which do not have isolated inputs. The patient's leads are connected to an isolation amplifier which provides isolation between the input and the output and has a high common mode rejection ratio. The output from the isolation amplifier is taken to the electrocardiographic monitor. The isolation amplifier not only provides additional patient safety but also reduces the level of $A C$ interference without interfering with any frequency components in the electrocardiogram.
\end{abstract}

The presence of AC interference in the electrocardiographic display is a cause for concern in many coronary care units and intensive care units. As well as the hazard of initiating ventricular fibrillation (Raftery et al., 1975), AC interference may also cause difficulty in interpreting the electrocardiogram which may thus be restricted in its usefulness as a diagnostic aid. There are many sources of interference, e.g. poor contact between electrode and skin or the use of long unscreened cables, and these have been outlined elsewhere (Monks, 1971). This paper describes the use of an isolation amplifier after all attempts to remove the source of the AC interference had failed.

The coronary care unit in which this work was carried out was situated in an old hospital building and the monitors did not have isolated input circuitry. After steps had been taken to eliminate all the usual sources of interference, the problem still persisted.

It was decided to investigate the possibility of using an isolation amplifier. The Model 273K from Analog Devices is a unity gain amplifier which provides isolation between input and output grounds and has a high common mode rejection ratio of $115 \mathrm{~dB}$ at $60 \mathrm{~Hz}$. Since it has a bandwidth from $\mathrm{DC}$ to $2 \mathrm{kHz}$, it does not interfere with any of the frequency components present in the signal as does a $50 \mathrm{~Hz}$ filter, but it does improve the signalto-noise ratio. Moreover, with older monitors which do not have isolated inputs, it eliminates any

Received for publication 8 September 1976 earth-borne interference and also provides added patient protection from earth leakage currents. The patient's leads are connected into the isolation amplifier and the output of the isolation amplifier is taken to the electrocardiograph monitor, with the connection between the isolator and monitor as short as possible. The only circuitry to be added is a power supply (two PP7 batteries), a switch, a voltage indicator, and a trimming resistor to calibrate the indicator (Fig. 1). This was incorporated in a metal housing which had a plate at the rear which fits over the bedrail (Fig. 2). This instrument is suitable only for a 3-lead electrocardiogram.

It was recognised during the design of the circuitry and housing that, to be most effective, the instrument should be easy to use. Since the interference presents only intermittently, the instrument is used only as required. When it is necessary to use the isolation amplifier, it is hooked over the bedrail; the patient's lead is removed from the monitor and connected to the isolation amplifier; the lead from the isolation amplifier is then connected to the monitor, and the instrument is switched on. A meter shows that the unit is on as well as indicating the voltage level of the batteries. With our circuitry the batteries require to be changed after 3 weeks of continuous use.

Fig. 3 shows a typical electrocardiogram obtained both with and without the use of the isolation amplifier and indicates the effectiveness of the instrument in removing AC interference from the electrocardiograph display. 


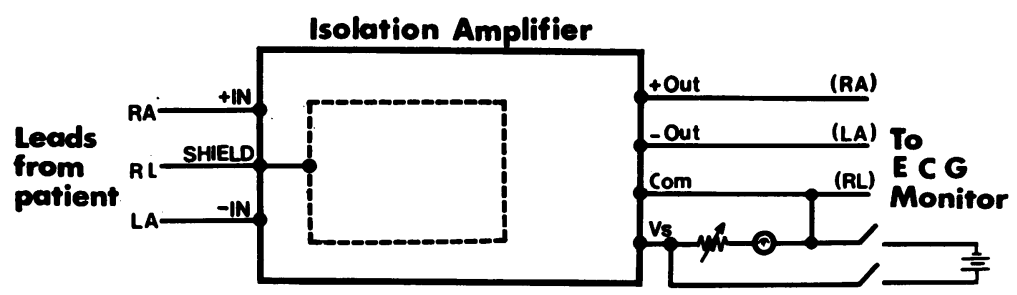

Fig. 1 Circuit diagram showing the incorporation of an isolation amplifier in lead I of a 3-lead electrocardiogram.

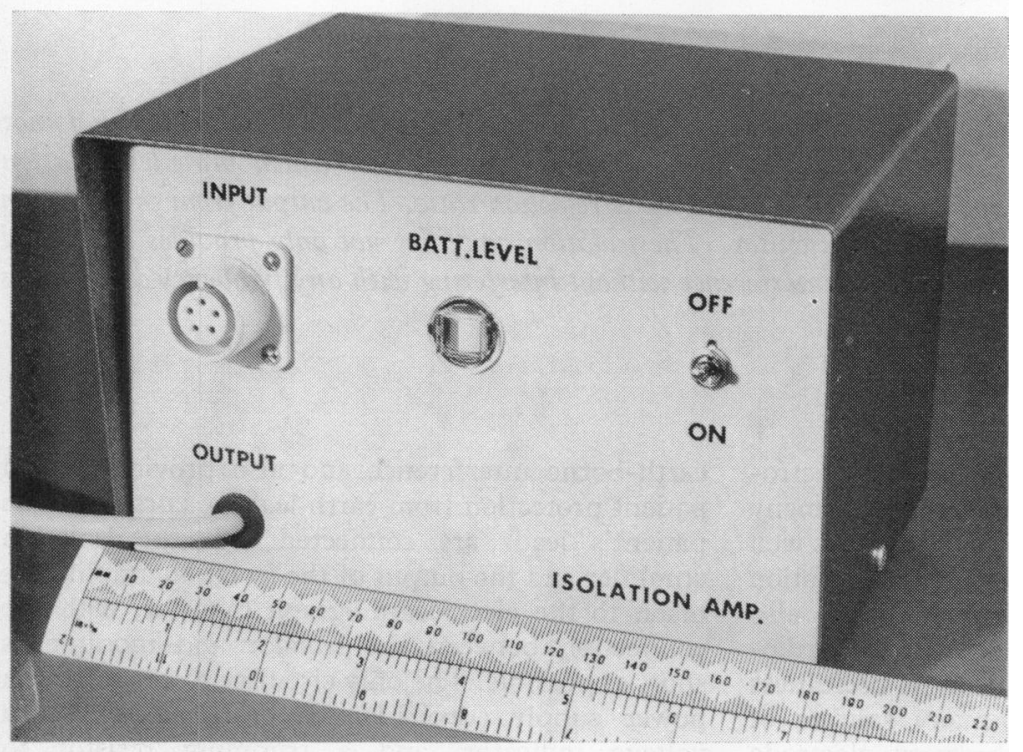

Fig. 2 Bedside unit which houses the isolation amplifier.

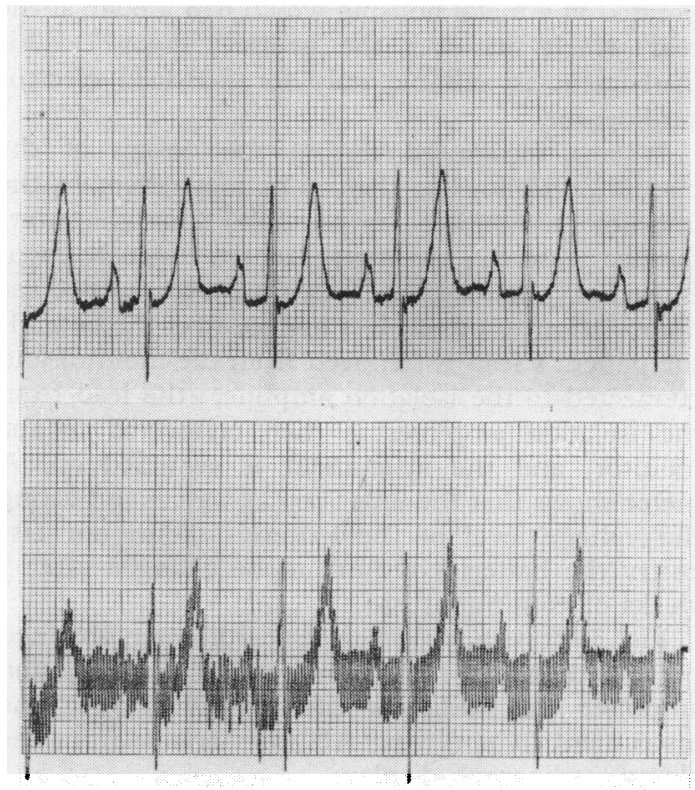

Fig. 3 Electrocardiograph display with (above) and without (below) isolation amplifier.

$\leftarrow$

\section{References}

Monks, P. S. (1971). Safe use of electro-medical equipment. Anaesthesia, 26, 264-280.

Raftery, E. B., Green, H. L., and Gregory, I. C. (1975) Disturbances of heart rhythm produced by $50 \mathrm{~Hz}$ leakage currents in dogs. Cärdiovascular Research, 9, 256-262.

Requests for reprints to H. Moseley, Esq., West of Scotland Health Boards, Department of Clinical Physics and Bio-Engineering, 11 West Graham Street, Glasgow G4 9LF. 